\title{
Introduction
}

\author{
Dean A. Shepherd
}

I have always been fascinated with how the mind works. What better way to pursue this passion than by exploring the minds of those directly involved in the entrepreneurial process? This entrepreneurial context is one where what an individual thinks and how he or she behaves is hugely consequential and these consequences, in turn, influence thinking, feeling, and acting. This 'mixture' of thoughts, feelings, actions and consequences often occur in a context of considerable time pressure, task complexity and uncertainty, and high performance variance. I feel that in exploring the psychology of entrepreneurship, we have the opportunity of operating beyond the existing boundary conditions of established theories of psychology, and thus can explore new domains, challenge existing assumptions, and generate new insights - new insights about entrepreneurship and new insights of interest to any psychology researcher with a passion for the extreme. Indeed, we have made some inroads along these lines.

Perhaps it was luck that started me on this journey. First, as an MBA student, I was influenced by a charismatic professor (Evan Douglas) who coached my team in a business plan competition, who fostered my passion for entrepreneurship research, and who took me from Australia to Northwestern University in the US for the final year of my PhD dissertation. We were both interested in why people choose an entrepreneurial career.

As the second student to complete a PhD in business at Bond University (a new university in Australia), I benefited from my predecessor (the first $\mathrm{PhD}$ student) whose accounting dissertation used conjoint analysis to investigate the decision policies of accountants. Based on this example, and with help from a marketing professor, I began to use metric conjoint analysis to investigate venture capitalists' assessments of entrepreneurs' entry strategies.

I was lucky to meet Andrew Zacharakis. We were both completing our dissertations using a similar decompositional approach - me with metric conjoint analysis and he with policy capturing. We recognized the challenges we would face in convincing reviewers of our "new approach' to entrepreneurship research and wrote a chapter that offered an explanation for how conjoint analysis works and what were its future possibilities (Shepherd and Zacharakis, 1997). Although we underestimated the initial challenges of introducing this new method to the entrepreneurship community of scholars, with persistence we achieved some success. But I think at the time we also underestimated the conceptual ground opened up by this methodological tool when applied to entrepreneurship-related questions.

Thinking about my early days working with conjoint analysis reminds me of a time when, after a presentation to the doctoral consortium at the Babson Research Conference, a PhD student told me that he thought I was like a boy and hammer; to a boy with a hammer everything looks like a nail. I certainly did see a lot of nails but conjoint was still only a tool - a means to open up interesting questions. I quickly moved from venture capitalists' assessments of entrepreneurs to the decisions of entrepreneurs themselves and then to those of other stakeholders. 
My research was also heavily influenced by a large negative event. As a doctoral student, I taught my students that businesses fail but entrepreneurs do not. Entrepreneurs learn from the failure and are more motivated than ever to achieve entrepreneurial success. But after class one day, I received a call from my dad and he told me how badly the family business was doing. I told him we had to close it down. This was devastating for him. It was devastating for me, seeing dad in such a negative emotional state, and while I did what I could do, it seemed there was little I could do to help him. I continued to teach my classes but the assumption that entrepreneurs automatically and instantaneously learn from failure just seemed, well, wrong. It was many years later as an Assistant Professor at the University of Colorado, I decided now was the time to research into the issue related to my family. I wanted to write this paper for myself. I wanted to set the record straight by talking about how at least some entrepreneurs react to business failure. I was confident that this prospective paper would never be published but that was okay. I knew that psychologists helped people overcome grief from the loss of a loved one and I thought that perhaps I could learn something from them that could help me find a way to help entrepreneurs of failed businesses like my dad. If I was going to be rejected I may as well be rejected from the best so I submitted my paper to the Academy of Management Review. Again, I was fortunate; I was assigned to an editor (Dev Jennings) who saw potential in the idea and who (along with the reviewers) helped me to develop the paper. The development and publication of this paper (Shepherd, 2003, Chapter 25 this volume) led to a stream of research on the consequences of failure, an interest in overcoming adversity, the role of emotions, and the intersection of emotions and cognitions.

My final piece of luck began one week into my job as an Assistant Professor at Rensselaer Polytechnic Institute. Young Rok Choi was a doctoral student in my department and he met with me to nervously ask if I would supervise his dissertation. After I stopped laughing, I told him that just a couple of months ago I was him - a doctoral student. But he persisted and I started the most rewarding aspect of my working life - working with doctoral students. At Colorado I was truly blessed to chair the dissertations of Jeff McMullen, Dawn DeTierne, Dennis Gregoire, and Mike Haynie (and also be on the committees for Andrew Corbett, Keith Brigham, Tim Read, Joy Godesiabois, Chuck Murnieks and others).

Jeff McMullen courageously went against convention and chose to work with an untenured assistant professor. I was honored. We worked together on a number of projects in the early years but the most interesting, I think, was a conceptual paper on third-person and first-person opportunity to understand entrepreneurial action (McMullen and Shepherd, 2006, Chapter 1 this volume). We have continued to work on this research theme (together and separately) ever since.

Dennis Gregoire focused on the first phase of the McMullen-Shepherd model. This research led to a dissertation that won the prestigious Helzer dissertation award and a number of papers of which I am incredibly proud (for example, Gregoire, Barr and Shepherd, 2010, Chapter 7 this volume; Gregoire and Shepherd, 2012, Chapter 8 this volume).

In working with Dawn DeTienne we focused on the other end of the entrepreneurial process - why some entrepreneurs persisted with poorly performing firms while others exited (DeTienne, Shepherd and DeCastro, 2008, Chapter 22 this volume). This topic resonated with me because perhaps my dad's persistence with the failing business cost our family more than it should have - we lost everything. 
Mike Haynie was interested in how entrepreneurs think and we began to explore how people think about their thinking and how this is particularly important in the entrepreneurial context (for example, Shepherd and Haynie, 2009; Haynie, Shepherd and Patzelt, 2010, Chapter 20 this volume). Mike Haynie went to Syracuse University as an assistant professor and, to cut a long story short, he introduced an entrepreneurship course to veterans disabled in combat in Afghanistan and Iraq. We worked together on a paper that attempted to capture this amazing transformation (Haynie and Shepherd, 2011, Chapter 18 this volume).

The story of my time at Colorado would not be complete without describing my meeting with Holger Patzelt. Holger had started his Management PhD in Germany (he already had a $\mathrm{PhD}$ in chemistry) and he contacted me saying that he wanted to use conjoint in his dissertation and asked whether he could he come to Colorado to work with me. Our first meeting was a little awkward. I read the first draft of a paper he was working on and it was, well, very bad (perhaps the worst draft I had seen). I gave him a lot of feedback. I did not see him again for two weeks, but when I did he had a second draft and it was fantastic - perhaps the best second draft I had seen. This started a wonderfully rewarding co-authoring relationship.

After being invited to join the faculty of Indiana University by Jeff Covin, I was quickly back working with doctoral students. Indeed, Rob Mitchell had me working with him on his proposal before I had officially started at IU. Rob and I combined experiments with conjoint analysis to further explore entrepreneurial decision making as it relates to opportunity (Mitchell and Shepherd, 2010, Chapter 9 this volume; Mitchell, Shepherd and Sharfman, 2011, Chapter 21 this volume). Rob won the NFIB dissertation award for his dissertation.

When working with Dan Holland on his dissertation we were both still fascinated with this notion of entrepreneurs' persistence with poorly performing firms and looked to values to gain additional insights (Holland and Shepherd, 2011, Chapter 23 this volume).

Hana Milanov wanted to work with me, and me with her, but she was intent on studying social networks and I knew nothing about the topic, and especially about the research methods involved. But we found common ground. She studied venture capitalists, which was the industry content for my dissertation, and, in the end, the theory relied heavily on psychology; specifically, social categorization (Milanov and Shepherd, 2013). Amazingly she was able to educate me in social network analysis (somewhat).

I remember every $\mathrm{PhD}$ student by at least one particularly enduring characteristic. For Marcus Wolfe, it was his answer to any request for more information, analysis, writing and so on - his answer was always 'consider it done'. And it always was. Marcus and I wanted to continue the exploration of the notion of grief in different contexts and we did so for his dissertation in the context of drug discovery (Wolfe and Shepherd, 2013a) but also conducted research on entrepreneurial grief over scientific projects (Shepherd, Patzelt and Wolfe, 2011, Chapter 28 this volume) and the loss of college football games (Wolfe and Shepherd, 2013b).

Brandon Mueller and I built on my earlier work with Dennis Gregoire to focus on how knowledge is transferred between expert and non-expert entrepreneurs (these papers are progressing through the review process).

It was not long after Trent Williams arrived into the doctoral program that I gave him a choice about a research project. I explained the project as one that required a lot of painstaking coding and that the project itself was high risk - that it may not lead to a publishable paper. I also explained that the project related to a bush fire in Australia that had destroyed my auntie's house, property, and animals (and would have killed her had she not been in town playing 
Bingo). I said I could pay him for his work or he could join me as a co-author. Fortunately, he chose the latter and made a huge contribution to the development of the paper. We found that in the aftermath of the Black Saturday, bushfires ventures spontaneously appeared to alleviate suffering. The initial paper was recently accepted for publication (Shepherd and Williams, 2014) and now Trent and I are exploring (1) the resilience of entrepreneurs who act to alleviate others' suffering, (2) the role of brokerage and resource management in entrepreneurs' compassion organizing, and (3) the entrepreneurial response to a disaster in a developing economy (Haiti). This has been a highly rewarding stream of research and working relationship.

\section{Organizing the book}

In describing how I came to investigate the psychology of entrepreneurship, I provide some context in which to understand the themes of this book. The themes are acting entrepreneurially, identifying opportunity, decision making, choosing and managing an entrepreneurial career, adapting and persisting, and recovering from entrepreneurial failure. The papers (as chapters) in each section are largely chronologically ordered to demonstrate (I hope) a progression of thought. Unfortunately, I was not able to include all relevant papers because of the publisher's limits. I hope my co-authors on these papers understand that a lack of inclusion in this book does not reflect a lack of belief in the importance of these papers.

I start the book with 'Acting Entrepreneurially' because these papers (chapters) provide a big picture of the entrepreneurial process within which many of the other themes of the book fit. In particular the second part, 'Identifying Opportunities' either builds on or complements the chapters of Part I.

In Part I, I begin with the model of entrepreneurial action that distinguishes between thirdperson and first-person opportunity (Chapter 1). Chapter 2 builds on this notion to focus on the antecedents of the formation of opportunity beliefs. Chapter 3 uses the notion of entrepreneurial action to link sustainable and development outcomes to promote a research agenda on sustainable entrepreneurship. Chapter 4 focuses on the decision to exploit an opportunity and the final chapter of the section (Chapter 5) extends the previous chapter by exploring the timing of the opportunity exploitation decision.

Part II is 'Identifying Opportunity'. It begins (Chapter 6) with a relatively simple test that both knowledge and financial reward facilitate opportunity identification. Chapter 7 investigates the cognitive process of structurally aligning aspects of the technology with market to identify opportunities. Chapter 8 builds on Chapter 7, to investigate the role that differences in the nature of the opportunities themselves have on their initial identification. Chapter 9 reports how both images of vulnerability and images of capability impact images of opportunity. The final chapter of this part (Chapter 10) explains how individuals can disengage their pro-environmental values in assessing opportunities that cause harm to the natural environment.

Part III is 'Decision Making'. Although many of the chapters throughout the book explore decision making, in this section I wanted to represent a variety of decisions in the entrepreneurial context, specifically the role of passion and excitement in the decision to exploit new product opportunities (Chapter 11); the role of overconfidence in biasing entrepreneurs' decisions regarding the creation and management of the ventures (Chapter 12); the decision policy of venture capitalists in their assessment of the probability of new venture survival (Chapter 13); and how academic entrepreneurs assess the attractiveness of different policy programs 
(Chapter 14). The final chapter of this part (Chapter 15) represents a reflection on where entrepreneurial decision making research has taken us and offers some suggestions for where it can lead in the future.

Part IV is 'Choosing and Managing an Entrepreneurial Career'. This part starts out with an investigation of the decision to pursue self-employment as a career option (Chapter 16). Chapter 17 explains the importance of fit between the cognitive style of the entrepreneur and the nature of the entrepreneurial task. Chapter 18 builds theory on career change when there has been a discontinuous, traumatic event that terminates a previously valued career path. Chapter 19 looks at how to manage the identity conflict that is so salient in an entrepreneurial career.

Part V is 'Adapting and Persisting'. This part begins with the role of metacognition in allowing individuals to cognitively adapt when performing an entrepreneurial task (Chapter 20). Chapter 21 offers a caution about changing strategic decisions when conditions have not changed, that is, erratic decision making. For the rest of the part we investigate the opposite to changing decision policies - choosing to persist. Chapter 22 explains why some entrepreneurs choose to persist with a poorly performing firm and others do not. Chapter 23 extends Chapter 22 by exploring more directly the roles of values and the experiencing of adversity. The final chapter of this section (Chapter 24) explores the financial and emotional trade-offs with delaying the decision to terminate a poorly performing firm.

Part VI is 'Recovering from Entrepreneurial Failure'. The first chapter of this part highlights how business failure can generate a negative emotional reaction that needs to be managed to facilitate learning from the experience (Chapter 25). Chapter 26 extends Chapter 25 to a family business and the role of 'others' (that is, the family) in helping deal with grief over the loss of the business. Chapter 27 takes the notion of entrepreneurial grief to the failure of a project and how organizations can either help their members regulate grief or normalize failure. Chapter 28 investigates how research scientists react and recover from project failure. The final chapter of this part (and the book; Chapter 29) explains why the failure of some projects generate more grief than others and explores the notion of self-compassion to reduce and regulate negative emotions to recover from the failure experience.

I personally toiled over whether or not to do this book in the first place - who am I to have a 'selected essays' book? Surely, I am no How ard Aldrich. But, I consulted with some colleagues (who I always turn to if I need some straight talk) and they thought it was a great idea. I hope you enjoy the result.

\section{References}

Haynie, M., and D.A. Shepherd (2009), 'A measure of adaptive cognition for entrepreneurship research', Entrepreneurship Theory and Practice, 33 (3), 695-714.

Milanov, H. and D.A. Shepherd (2013), 'The importance of the first relationship: The ongoing influence of initial network on future status', Strategic Management Journal, 34 (6), 727-50.

Shepherd, D.A. and T.A. Williams (2014), 'Local venturing as compassion organizing in the aftermath of a natural disaster: the role of localness and community in reducing suffering', Journal of Management Studies, 51, 952-94.

Shepherd, D.A. and A. Zacharakis (1997), 'Conjoint analysis: a window of opportunity for entrepreneurship research', in J. Katz (ed.), Advances in Entrepreneurship, Firm Emergence and Growth, Greenwich, CT: JAI Press, $203-48$.

Wolfe, M.T. and D.A. Shepherd (2013a), 'What Do You Have to Say About That? Performance Events and Narratives' Positive and Negative Emotional Content', Entrepreneurship Theory and Practice, forthcoming.

Wolfe, M.T. and D.A. Shepherd (2013b), “"Bouncing Back” From a Loss: Entrepreneurial Orientation, Emotions, and Failure Narratives', Entrepreneurship Theory and Practice, forthcoming. 
Dean A. Shepherd - 9781783479801 Downloaded from PubFactory at $04 / 26 / 2023$ 03:21:43PM via free access 